\title{
The Strengths, Weaknesses, Opportunities and Threats (SWOT) Analysis of Mycobacterium tuberculosis: A Systematic Review
}

\author{
Michael Oluyemi Babalola \\ Epidemiology, Molecular Virology, and Special Pathogens Unit, Department of Microbiology, \\ Adekunle Ajasin University, Akungba Akoko, Nigeria \\ Email: mikeolubabs@yahoo.com
}

Received 30 October 2015; accepted 25 December 2015; published 28 December 2015

Copyright (C) 2015 by author and Scientific Research Publishing Inc. This work is licensed under the Creative Commons Attribution International License (CC BY). http://creativecommons.org/licenses/by/4.0/

(c) ()) Open Access

\section{Abstract}

Background: Mycobacterium tuberculosis, the etiology of pulmonary and extra pulmonary tuberculosis is taunted to have predated the existence of mankind, and science has elucidated its presence in old Egyptian' mummies, as it continues to evade current antibiotic treatments, wreck the havoc and decimate human populations. Presented here, are the Strengths, Weaknesses, Opportunities and Threats (SWOT) analysis of Mycobacterium tuberculosis, and the first proposal for the application of this innovative concept in the field of Tuberculosis research, to proffer holistic platform, focused knowledge, and strategies at undermining the prowess of the tubercle bacilli and overcoming its scourge. Materials and Methods: A systematic review was carried out to mine data on the strengths, the weaknesses, the opportunities and threats to $M$. $t b$, by review of several publications using meaningful theme and specific search phrases on the subject. Results: Strengths of Mycobacterium tuberculosis include: possession of abundant cell wall mycothiol; $M$. $t b$ is highly contagious and requires low infectious dose (ID50) to establish infection; ability to specifically target and replicate in the host' macrophages; ability to establish extrapulmonary multiorgan involvement; dual polymorphism i.e. existence in both an actively replicating form as well as or latent state; assumption of variable metabolic states; delayed seeding from the lungs of the replicating bacteria cells to the mediastinal lymph nodes; delayed macrophage apoptosis prior to bacterial growth and ultimate cellular necrosis; ability to shift to glyoxylate pathway during lipid metabolism in lieu of glucose during persistence phase in the host. Weaknesses of $M$. tuberculosis include: the requirement for growth of a membrane protein called Rv3671c during in vivo replication for survival in the acidic milieu of the macrophages and phagosome; $M$. $t b$ is a fastidious slow growing bacterium with long generation time; establishment of productive infection in less than $10 \%$ of infected subjects; the bacterium is strictly an intracellular aerobic pathogen; and variable 
bacteria level of adenosine triphosphate. Opportunities harnessed by $M$. $t b$ include: development and spread of resistant strains owing to inadequate and inappropriate drug treatment; limited efficacy and use of BCG Vaccine; MDR-TB is under-diagnosed in children; pathogenic synergy of coinfection of the Human Immunodeficiency Virus (HIV) and Mycobacterium tuberculosis (MTB); difficulty of TB screening in HIV-infected persons; immune status of the host; immigration; slow response of the cellular immune response to $M$. $t b$ which enables constant endogenous reinfection of the host; anatomical vulnerability of the lungs; aerosols by inspired air is crucial for latent tuberculosis infection. Threats to $M$. tuberculosis include: the development and use of sensitive combination of microbiological tests as the gold-standard in HIV infected patients; annual TB test; selective isolation of TB patients by reintroduction of sanatoria; prioritizing genomic drug targets; sustenance of the global TB funds; development of potent vaccine; live imaging using computer tomography and positron electron tomography to characterize active TB in lesions; development and application of Infecton for imaging deep seated infections.

\section{Keywords}

SWOT Analysis, Mycobacterium tuberculosis, Mycothiols, Glyoxylate Pathway, Rv3671c, HIV Coinfection, Lungs Vulnerability, Live Imaging, Infecton, Vaccine

\section{Introduction}

Mycobacterium tuberculosis was discovered and described by Robert Koch on 24 March 1882, about 130 years ago, as the causative agent of tuberculosis (TB). The bacterium is an acid fast bacillus with unique cell wall composition. Under Light microscope, the tubercle bacilli typically appear as straight or slightly curved rods. In response to growth conditions and age of the culture, bacilli may vary in size and shape from coccobacilli to long rods. The dimensions of the bacilli have been reported to be 1 - $10 \mu \mathrm{m}$ in length (usually 3 - $5 \mu \mathrm{m}$ ), and 0.2 $0.6 \mu \mathrm{m}$ in diameter. The possibility of morphological variations in tubercle bacilli was suggested by few investigators that under unfavorable conditions, i.e., a limited nutrient supply, or oxygen deprivation, Mycobacterium assumed a swollen appearance without forming the vacuolar or globoid bodies. Advances in microscopic technique i.e., transmission electron microscope (TEM), scanning electron (SEM) and atomic force microcopy (AFM), have shown that the bacillus does not always manifest itself in the classical rod shape (Figure 1).

They become shorter in older cultures, filamentous within macrophages and ovoid during starvation [1] and they may produce buds and branches in extensively drug resistance strains (XDR-TB). These variations are thought to be advantageous in stressful conditions of osmotic shock or desiccation as well as contributing to their considerable resistance to many drugs.

Globally, the mortality attributed to tuberculosis was reported to be about 4700 per day and accounted for 1.7 million deaths in 2009. However, in 2011, there were an estimated 8.7 million new cases of tuberculosis and 1.4 million deaths from TB [2]. It was predicted that between 2002 and 2020, 36 million people would have died from TB [3].

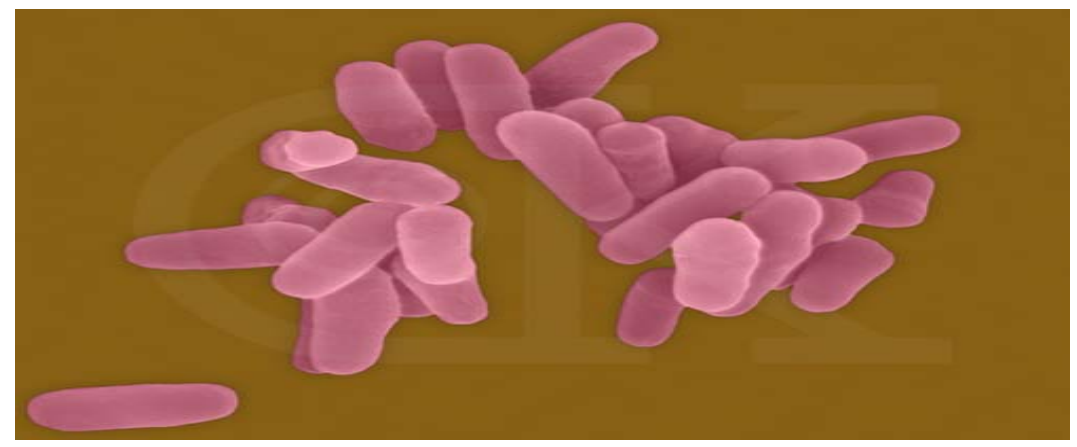

Figure 1. Morphological variations of $M$. tb cells [1]. 
M. tuberculosis infection occurs via aerosol, and inhalation of only a few droplets containing the tubercle bacilli is sufficient for the pathogen to infect the lungs (Figure 2). Once the organism is in the lungs, the bacteria are phagocytosed by macrophages, which migrate to the hylar lymph node and elicit a CD4 T-cell mediated hypersensitivity response that forms small, hard, nodules called tubercles which are characteristics of tuberculosis and give the disease its name.

Subsequently, the pathogenesis of $M$. tuberculosis infection occurs in two stages. The first stage, latent TB, an asymptomatic state that can persist for many years in the host, requiring only a weakened immune response to become activated [4]. In the second stage, active TB, the bacteria begins to replicate and the disease manifests in lingering, chronic cough that produces phlegm or sputum, sometimes with bloody streaks, fever, chills, night sweats, unexplained weight loss, fatigue and chest pain. If untreated or in the event of treatment failure, the threshold of the disease is eventual death of the patient. The WHO estimates that infected adults lose an average of 3 - 4 months of work while recuperating from TB disease and an average of 15 years of economic activity is lost from each adult TB death.

\section{Search Criteria}

\section{Definition and Identification of the SWOT Parameters in Mycobacterium tuberculosis}

The parameters of the SWOT concept (the Strengths, the Weaknesses, the Opportunities and Threats) were first defined, and numerous research publications on Mycobacterium tuberculosis were reviewed to identify the parameters as applicable to the bacterium. The identified factors were then allocated to each parameter as they were determined, and discussed.

\section{Literature Review}

\subsection{Strengths of Mycobacterium tuberculosis}

The Strengths of $M$. $t b$ are the biological characteristics or attributes of internal origin which are helpful in achieving the pathogenic objective, the survival and establishment of infection by the bacterium. These include:

Possession of abundant cell wall mycothiol. The mycobacteria cell wall is composed of abundant mycolic acids, complex waxes, and unique glycolipids. The mycolic acids consist of extremely long Carbon side chains $\left(\mathrm{C}_{60}\right.$ to $\left.\mathrm{C}_{90}\right)$ joined to the muramic acid moiety of the peptidoglycan by phosphodiester bridges, and to arabinogalactan by esterified glycolipid linkages (Figure 3 and Figure 4). Species variations are characterized by variation in sugar substitutions in the glycolipids or peptidoglycolipids. The mycobacterial cell wall is acid-fast (i.e., it retains carbolfuchsin dye when decolorized with acid-ethanol). This important property allows differential staining in contaminated clinical specimens such as sputum. Other important cell wall components are trehalose dimycolate (so-called cord factor, as it is thought to induce growth in serpentine cords on artificial medium).

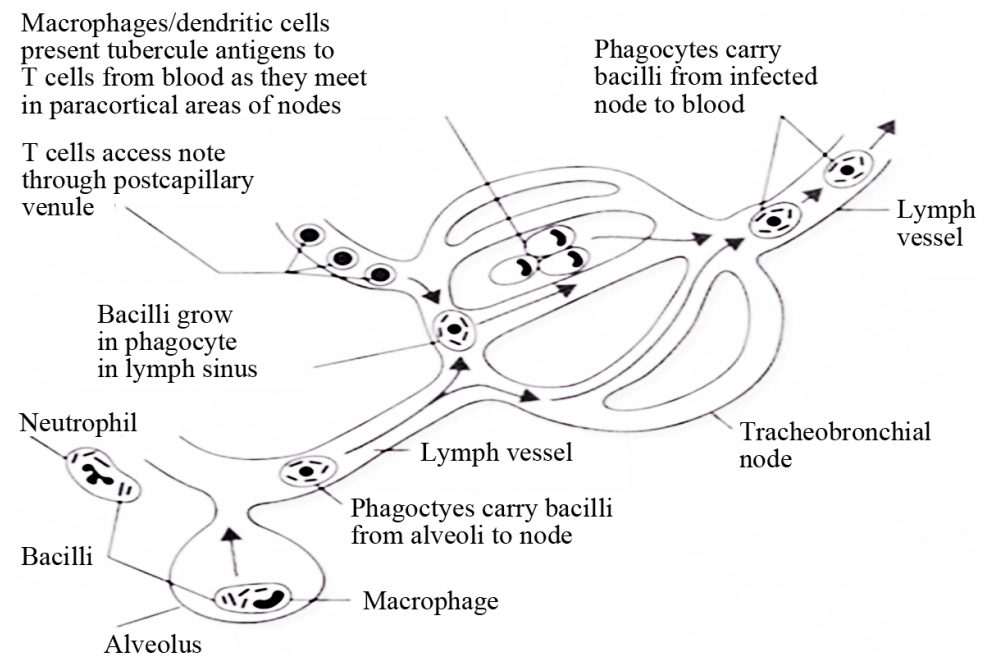

Figure 2. Pathways of $M$. $t b$ infection and dissemination [4]. 


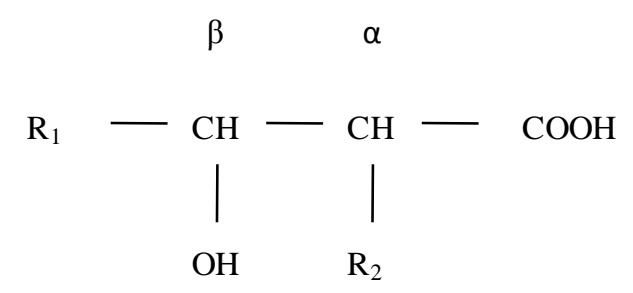

Figure 3. Molecular structure of mycolic acid [5].

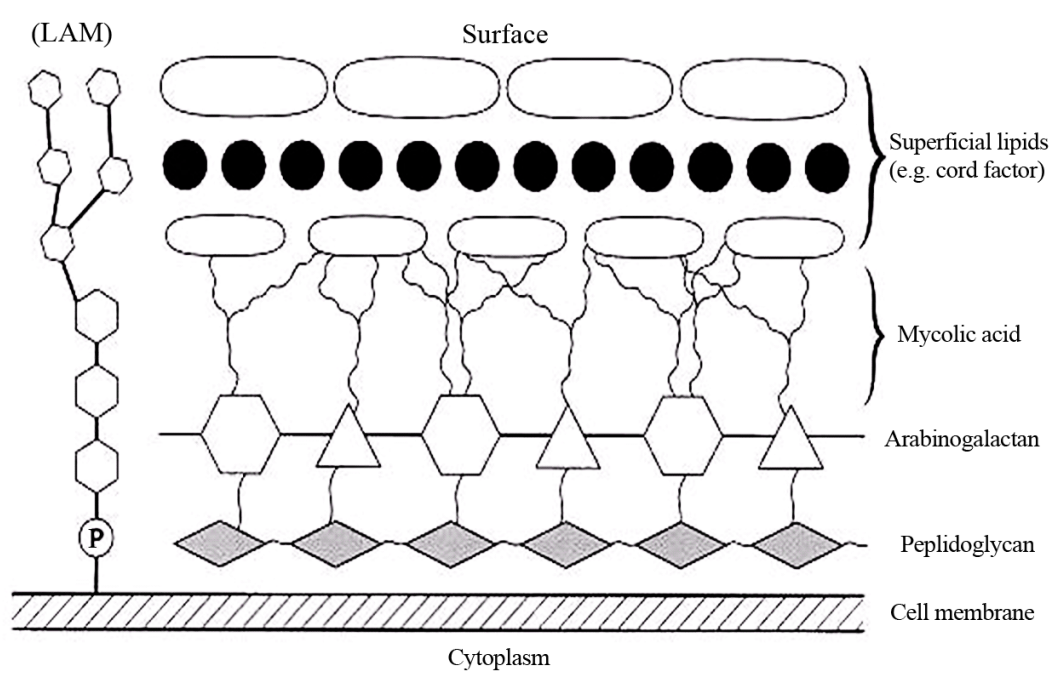

Figure 4. Complex cell wall structure of mycobacteria [5].

On solid media the colonies are raised and rough with a wrinkled surface. The cells grow either as discrete rods or as aggregates. Virulent strains tend to grow as an aggregated long arrangement called serpentine cord. Cord factor is a derivative of mycolic acids, trehalose-6, 6-dimycolate (Figure 5) which destroys mitochondria, causes chronic granulomatosis, and suppresses WBC wandering.

Mycobacterial sulfolipids, which may play a role in virulence by suppressing phagosome combination with lysosome.

Another unique constituent which may contribute to pathogenesis is Lipoarabinomannan (LAM). Purified LAM from virulent and attenuated strains of mycobacteria may differ structurally, and these differences may contribute to their varying abilities to stimulate cytokine production in mononuclear cell cultures [5].

The Mycothiol is a major, low molecular weight cellular thiol that is unique to mycobacteria and responsible for protection of the bacteria against oxidative stress and survival. This accounts for impermeability and resistance to antimicrobial agents, resistance to killing by acidic and alkaline compounds in both the intracellular and extracellular environment, and resistance to osmotic lysis by lysozyme [6]. M. tuberculosis contains 4 homologous copies of an operon designated mammalian cell entry 1 - 4, (mce1-4), which resembles ATP-Binding Cassette (ABC) transporters possibly involved in lipid importation [7]. These mce operon proteins are located in the cell wall [8]. Numerous reports have suggested that mce1 operon is involved in fatty acid transport and metabolism. A phylogenomic analysis of the M. tuberculosis mce operons revealed that related operons are widely distributed among members of Actinomycetales and that they encode a subfamily of ABC lipid uptake transporters that may be involved in remodeling the cell envelope [9]. Therefore, the lipid-rich cell wall of $M$. tuberculosis may contribute to the mechanism of persistence in the host, by dynamic structural alterations during a course of infection, which may serve as an adaptive strategy for this organism [10]. However, the stated strengths in this category (trehalose dimycolate, mycobacterial sulfolipids, lipoarabinomannan, mce operon proteins) may be utilized as potential targets for new selective antituberculous drugs capable of effecting cidal actions by chelating the bacterium cellular thiols and creating pores for leakage of its internal components, without any toxic effects on the host cell. 


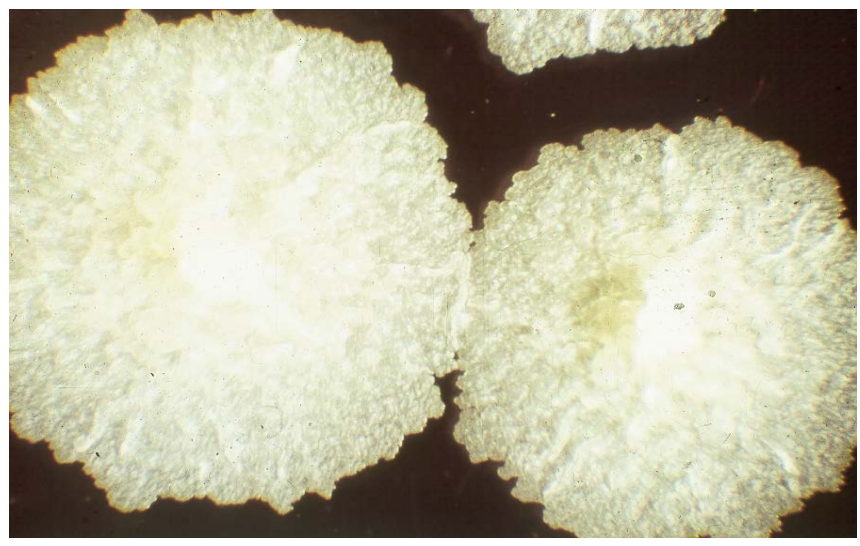

Figure 5. Serpentine cord formation in $M$. tb culture.

$M$. $t \boldsymbol{b}$ is highly contagious and requires low infectious dose to establish infection. Tuberculosis is most commonly spread by aerosol. When a person with active pulmonary TB exhales, coughs, sneezes, or even talks, tiny droplets containing bacteria are produced that can be inhaled by others. Inhalation of these droplet nuclei can result in infection. Between 5 - 200, inhaled bacilli are usually necessary for infection. One droplet nuclei contains no more than 3 bacilli. Droplet nuclei are so small that they can remain air-borne for extended periods of time. The most effective (infective) droplet nuclei tend to have a diameter of 5 micrometers. Droplet nuclei are generated during talking, coughing and sneezing. Coughing generates about 3000 droplet nuclei, talking for 5 minutes generates 3000 droplet nuclei, while singing generates 3000 droplet nuclei in one minute. Sneezing generates the most droplet nuclei by far, which can spread to individuals up to 10 feet away [11].

Ability to specifically target and replicate in the macrophages facilitate survival and dissemination. As an intracellular pathogen, the establishment of a successful infection by M. tuberculosis depends on the initial encounter with the host macrophages, which represent the first line of cellular defense against microbial invasion. At the interface between mycobacterial and macrophages, the complex outermost layer of the mycobacterial cell wall probably plays a role in facilitating entry to the host cell. The bacillus binds directly to mannose receptors on macrophages via the cell wall-associated mannosylated glycolipid, LAM, or indirectly via certain complement receptors or Fc receptors. The bacterium possession of ure $C$ gene prevents maturation of the acidic phagosomes in macrophages, while the cord factors inactivate mitochondrial membranes of phagocytes. These are thought to be major strategies that allow them to survive and multiply within macrophages. This strength can be decreased and harnessed as potential for elimination of the bacterium, by development of new integrated antitubercular drugs that prevents entry into the macrophages by either blocking the mannose receptor and/or prevent synthesis of the $u$ reC gene products.

Ability to establish extrapulmonary multiorgan involvement rather than strictly localized infection. $M$. $t b$ has the capacity to invade other organs in the body by various mechanisms. Disseminated tuberculosis (TB) is characterized by hematogenous or lymphatic spread of Mycobacterium tuberculosis from the lungs to other parts of the body. Phagocytes with ingested mycobacteria may act as vehicles, transporting the agent to various anatomical sites in the body. Infection may spread to regional lymph nodes from the initial site through lymphatics. If a caseating lesion discharges its contents into a bronchus, they may be aspirated and distributed to various parts of the lungs. If this discharge is swallowed, it would infect the stomach and intestine. Mycobacteremia disseminates bacilli to all organs (miliary distribution). This characteristic may be attributed to the survival of the bacterium in aerobic milieu, as virtually every organ in the body require oxygen. The bacteria can spread or colonize the nasopharynx after which they cross the mucosal barrier and enter the blood stream and cerebrospinal fluid where they produce inflammation of the meninges, which results into tuberculous meningitis (TBM). Many organs and bones, including the brain, pericardium, kidneys, gastrointestinal tract, and spine, can become involved and be damaged by the infection. The symptoms vary depending on the area of the body that is affected. Some examples include back pain and paralysis (spinal TB), weakness due to anemia (TB in the bone marrow), altered mental state, headache, and coma (TBM), joint pain or abdominal pain [12]. TBM is prevalent in both under-developed and developing countries, and is one of the commonest and serious forms of extrapulmonary tuberculosis in many countries. TBM is more common in adult females and in children in the first 5 
years of life. The diagnosis of TBM has been problematic as the clinical manifestations can be confused with those of other chronic infections of the central nervous system such as Neurocysticercosis (NCC) and cryptococcal meningitis. However, Immunoassays like Cell-ELISA, Reverse passive haemagglutinaton assay (RPHA) and Western blotting, are the recent best available diagnostic tools to strengthen the suspicion especially if evidence of extracranial tuberculosis (TB) is found.

For laboratory diagnosis of tuberculous meningitis 2 - $5 \mathrm{ml}$ of cerebrospinal fluid can be withdrawn from patients using a lumbar puncture and subjected to routine bio-chemical analysis and pathological analysis like AFB, culture and western blot using SDS-PAGE to reveal increased protein, decreased glucose, lymphocytic predominance, presence of Mycobacterium tuberculosis, as well as a 30-KDa protein band antigen that is specific to Mycobacterium tuberculosis as a marker for tuberculous meningitis, respectively. Treatment must be started as soon as there is reasonable suspicion of TBM while waiting for confirmation of the diagnosis, as delay may lead to mental retardation, cranial nerve palsies and organic brain syndrome in adults [13]. Adoption of neurosurgical intervention to relieve hydrocephalus, drain the tubercular brain abscess and break the optochiasmatic adhesions to prevent blindness is imperative.

Difficulty in the characterization of active TB. Part of the reason why latent TB is a relatively neglected area of research is that it is difficult to characterize. Early studies of latent TB were based on autopsy of lung tissue samples, which gave confusing results, differing greatly from one study to the next [14]. Modern methods, which rely on skin tests, are not much more accurate. When someone gets exposed to TB, they usually produce immune cells (T-cells) specific to the bacteria. If a skin test is performed, we can confirm this type of T-cell. But you cannot confirm whether they are still carrying the infection or whether their immune system has got rid of it.

Ability of $M$. tb to shift to glyoxylate pathway during lipid metabolism in lieu of glucose, during persistence phase in the host. Persistence may be defined as a stage where the metabolic downshift to anaerobiosis brings about a nutritionally suspended condition. In the granulomas, the bacterium does not replicate and becomes inert yet surviving in occult forms to get activated in immune-compromised situations. In persistent phase the substrate is changed from glucose to lipids, glycolysis is decreased and the glyoxylate shunt is upregulated allowing anaplerotic maintenance of the tricarboxylic acid (TCA) cycle [15]. The glyoxylate shunt converts isocitrate to succinate and glyoxylate, catalyzed by the enzyme isocitrate lyase (ICL), followed by the addition of Acetyl-CoA to glyoxylate to form malate by malate synthase (MS) [16] (Figure 6). The glyoxylate shunt allows the bacteria to avoid the carbon dioxide generating steps of the Krebs cycle, enabling them to shunt carbons from fats to carbohydrate synthesis [17]. The treatment today is focused at reducing the treatment time line (presently between six to nine months), by evolution of new antituberculous drugs to replace or augment the current ones which were discovered over forty years ago. Targeting pathways that get triggered during persistence phase can yield potential leads [18]. As humans do not have functional glyoxylate pathway, the enzymes of the pathway are promising drug target thereby eliminating the potential adverse effects of toxicity. The relative abundance of genes pertaining to fatty acid degradation in mycobacterial genome highlights the importance of survival on host's derived lipids in vivo [19]. Over 200 genes are identified as encoding enzymes for the metabolism of fatty acids. This large number of $M$. tuberculosis enzymes that putatively use fatty acids may be related to the ability of the pathogen to grow in the tissues of the infected host, where fatty acids may be the major carbon source.

Dual polymorphism. Mycobacterium tuberculosis exists in actively replicating or latent states. The bacteria colonies live in a mix of these states, the proportion affecting whether an infected person exhibits symptoms. In latent TB, a person does not fall ill unless the bacteria develop into the active form, which happens to 1 in 10 infected people. In active TB, the bacteria divide, causing damage and disease; while in latent TB the bacteria lie dormant. This led to the realization that the non-replicating bacteria constitute a significant part of the problem in treating active TB. The drug treatments regime of TB takes an arduous six to nine months, because in the early month, the drug eliminates all the actively replicating bacteria, but has to be extended to kill the non-replicating bacteria. $M$. tuberculosis is only vulnerable when it is dividing. If the drug happens to be there when it replicates, then it can be inactivated. As the drugs require the cells to be metabolically active to be potent, current TB drugs cannot kill the bacteria when latent, which may explain why treatment regimes require six to nine months and may not completely eliminate the infection. Therefore, drugs that target both the active and latent forms could make eliminating TB a realistic goal.

Ability of the bacterium to assume variable metabolic states: dormancy, latency, persistence, stationary phase and non-replicating persistence. The ability to adapt to different conditions is a key for $M$. tuber- 


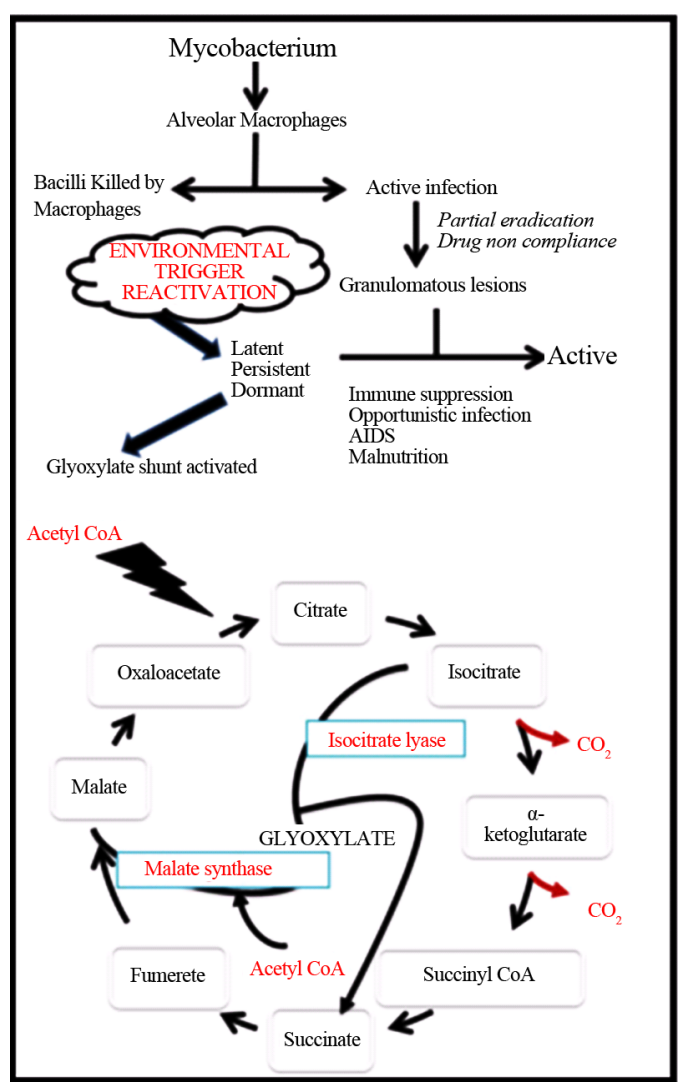

Figure 6. Mycobacterium survival: the lipid lunch through glyoxylate shunt [16].

culosis to successfully infect human hosts. Adaptations allow the organism to evade the host immune responses during acute infections and persist for an extended period of time during the latent infectious stage. Although these terms could signify the same, they describe to some extent different states and circumstances related to Latent Tuberculosis Infection (LTBI). (LTBI) is usually defined as presumptive infection with M. tuberculosis complex, as evidenced by a positive tuberculin skin test reaction and/or a positive interferon- $\gamma$ release assay (IGRA) without any sign of overt disease [20]. In latently infected individuals, estimated to include one-third of the human population, the organism exists in a variety of metabolic states, which impedes the development of a simple strategy for controlling or eradicating this disease. LTBI status is characterized by the absence of clinical, and radiological evidence of TB disease and the diagnosis is performed by Immune test that ascertains $M$. $t b$ specific immune response (positive TST or an IGRA) due to a condition where human tissues contain living $M$. $t b$ that persists in a state of altered metabolism that potentially may later reactivate. However, the biological nature of latent infection with $M$. tuberculosis is controversial. Direct identification of individuals who are latently infected with live $M$. tuberculosis without active tuberculosis is currently not possible. The tests available in clinical practice to identify individuals with latent infection with $M$. tuberculosis, the in vivo tuberculin skin test and the ex vivo IGRA, are designed to identify a memory of an adaptive immune response against mycobacterial antigens, rather than to identify true latent infection. The proportion of individuals with a persistently positive immune response against $M$. tuberculosis by tuberculin skin test or IGRA who are truly latently infected with live mycobacteria is unknown [21]. This factor portends critical challenge to curtail $M$. $t b$ disease. The term "dormancy" describes the ability of the bacilli to remain for long periods in a state of low metabolic activity, from which they can resume future active growth. "Latency" reflects the ability of the bacilli to remain in the infected host for a long time. "Persistence" is linked to the ability of the bacilli to survive in the host even after being treated with chemotherapy for a long time. "Stationary phase" has been used to refer to the late plateau seen in the growth curves of many different bacterial species when cultured in vitro, due to a stop of the exponential growth when there is a change in the optimal growth conditions (often without precisely defining the 
term). "Non-replicating persistence" is a definition that makes no assumptions about the mechanisms involved in the lack of growth of bacilli [14]. At this particular LTBI stage in the host, the combinations of these interwoven circumstances existed and utilized by the bacteria population to develop active disease. As a measure, preventive treatment of LTBI can be adopted purposely to eliminate the bacteria that may survive undetected in the body after infection. In infected people, proper treatment prevents about $90 \%$ of cases from developing active tuberculosis. The targeted candidates for preventive chemotherapy include recently infected individuals who have the highest annual risk for development of active TB in the first 2 years following infection, and individuals who belong to groups with an increased risk for the future development of TB (these include close recent contacts of patients with active tuberculosis, especially small children), patients with silicosis, HIV-infected individuals, individuals undergoing certain types of TNF-antagonists therapies, patients with gastrectomy, jejuno-ileal bypass surgery, and a host of other factors. In a second step, among the individuals in these groups those with no risk of tuberculosis (no evidence of infection with M. tuberculosis) are excluded. In small children, the risk for the development of tuberculosis is so high, that being a household contact is a sufficient justification for prophylactic chemotherapy without any further testing apart from excluding active tuberculosis. Direct knowledge of the metabolic states of M. tuberculosis in patients would aid in the management of the disease as well as in forming the basis for developing new drugs and designing more efficacious drug cocktails.

Delayed seeding from the lungs of the replicating bacteria cells to the mediastinal lymph nodes. The immune response against $M$. tuberculosis are mainly directed against the growing bacilli [22] and in particular against antigens secreted to the external milieu, which can be obtained after filtration of homogenates from the log phase in in- vitro cultures ("culture filtrate proteins", i.e. ESAT-6 and Ag85 complex). The initiation of the immune response to $M$. tuberculosis depends on transport of live bacteria from the lungs to the mediastinal lymph nodes. Strategically, M. tuberculosis delays this process to expand the bacterial population in the lungs and to evade immune effector mechanisms, thereby establishing chronic infection [23].

Delayed macrophage apoptosis prior to bacterial growth and ultimate cellular necrosis. All of the growing machinery of $M$. tuberculosis seems to be adapted to being phagocytosed by macrophages in order to start intracellular growth [24]. Evidence of this adaptation is that, by avoiding phagosome-lysosome fusion, $M$. tuberculosis enters the log phase, avoids macrophage apoptosis which would prevent bacterial growth [25]. However, the macrophage usually becomes necrotic once the bacillary concentration is high enough to induce necrosis, probably because of the presence of toxic molecules. The fact that $M$. tuberculosis induces necrosis provides a major distinction when comparing with bacteria of similar phenotype, for instance with $M$. avium [26]. Once in the extracellular milieu, the growth stops and the stationary phase starts. This point might be the beginning of the nonreplicating status (or dormancy) since the extracellular milieu is abundant in the bactericidal enzymes' reactive oxygen and nitrogen intermediates (ROI and RNI). It also has a low pH as a consequence of the high destruction of neutrophils and macrophages that liberate their intracellular contents [27]. This non-replicating status ends once the extracellular bacilli are phagocytosed by new incoming macrophages, at which point the bacilli probably go through a lag phase to start the log phase once again.

Intrinsic resistance of non-replicating bacilli. These bacillary forms are more resistant to stress than the growing bacilli [28]. It appears that non-replicating bacilli would be mostly phagocytosed and would resist killing by activated macrophages. An explanation for this phenomenon may also reside in the progressive decrease of bactericidal activity due to the simultaneous phagocytosis of cellular debris and the accumulation of LBs. This phenomenon leads to the induction of FMs, which can only reinforce the non-replicating status of the bacilli.

Growth in microaerophilic condition. Contrary to the previous belief that the bacterium was strictly aerobic, there are numerous experimental indicators that the bacterium can grow in microaerophilic environments, especially during the later stages of infection, e.g., in lung granulomas. Wild type M. tuberculosis has been shown to possess an inducible nitrate reductase which allows respiration using $\mathrm{NO}_{3}$ as a final electron acceptor. If anaerobic or microaerophilic growth is an important feature of $M$. tuberculosis physiology during infection, the existence of nitrate reductase could be a significant factor in sustaining growth under these conditions [29].

Antigenic mimicry via Antigen 85 complex. This complex is composed of a group of proteins secreted by $M$. $t b$ that are known to bind fibronectin. These proteins may aid in walling-off the bacteria from the immune system and may facilitate tubercle formation.

Expression of adhesins is central to pathogenesis. Multiple $M$. tuberculosis proteins capable of interacting with receptors on host cells to facilitate binding to mammalian components have been identified. These include 
laminin binding protein involved in cyto-adherence by its recognition of laminin. Glyoxalate pathway enzyme, malate synthase (glcB; Rv1837c), binds to the human ECM proteins laminin and fibronectin and is an anchorless adhesin. The $19 \mathrm{kDa}$ lipoprotein antigen (Rv3763) present on the cell wall preferentially binds to THP-1 macrophage-like cells. The cell surface glycoprotein alanineproline-rich antigen (Apa, Rv1860), initially considered a secreted molecule, has been shown to transiently associate with the cell wall to allow attachment to the pulmonary surfactant protein-A (PSP-A). The Cpn60.2 molecular chaperone protein (GroEL2; Rv0440), believed to be involved in bacterial pathogenicity and considered essential for cell viability appears to be necessary to facilitate efficient bacterial association with macrophages. Kumar et al. [30] identified Rv2599 (membrane protein), Rv0309 (L,D-transpeptidase) and Rv3717 (N-acetylmuramoyl-L-alanine amidase) as novel adhesins of M. tuberculosis H37Rv, capable of binding to laminin and fibronectin (Figure 7).

The most characterized and major adhesin in $\mathrm{M}$. tuberculosis is the $28 \mathrm{kDa}$ heparin-binding haemagglutinin adhesion (HBHA). This is a surface-exposed protein, a virulence factor that facilitates the dissemination of $M$. tuberculosis from the site of primary infection by initiating interaction with host epithelial cells. The two crucial steps in TB pathogenesis, namely bacterial aggregation and cell adhesion, are facilitated by HBHA [32]. HBHAmediated aggregation is instrumental in the formation of bacterial clumps, allowing for more effective adherence and invasion. In M. tuberculosis, the single malate synthase encoded by glcB is thought to play a key role in pathogenesis by imparting some degree of virulence to the bacteria. These findings demand further research into identifying and characterizing $M$. tuberculosis adhesins to elucidate their precise role in virulence establish the mechanisms behind their secretion and identify the receptors required for their association with the host cell surface. Such studies could potentially result in the development of novel strategies for infection control by means of therapeutics or vaccines that are able to block secretion and/or prevent reassociation with the cell membrane. Exposure to M. tuberculosis antigens leads to the production of specific antibodies, which may be used as markers of infection in serological tests. For instance, malate synthase, an anchorless adhesin is a surrogate serodiagnostic marker for TB infection in HIV seropositive individuals.

\subsection{The Weaknesses of Mycobacterium Tuberculosis}

The Weaknesses of $M$. $t b$ are the attributes of internal origin and requirements for achieving pathogenic objective, survival and establishment of infection, which invariably are harmful, and present as potential targets for

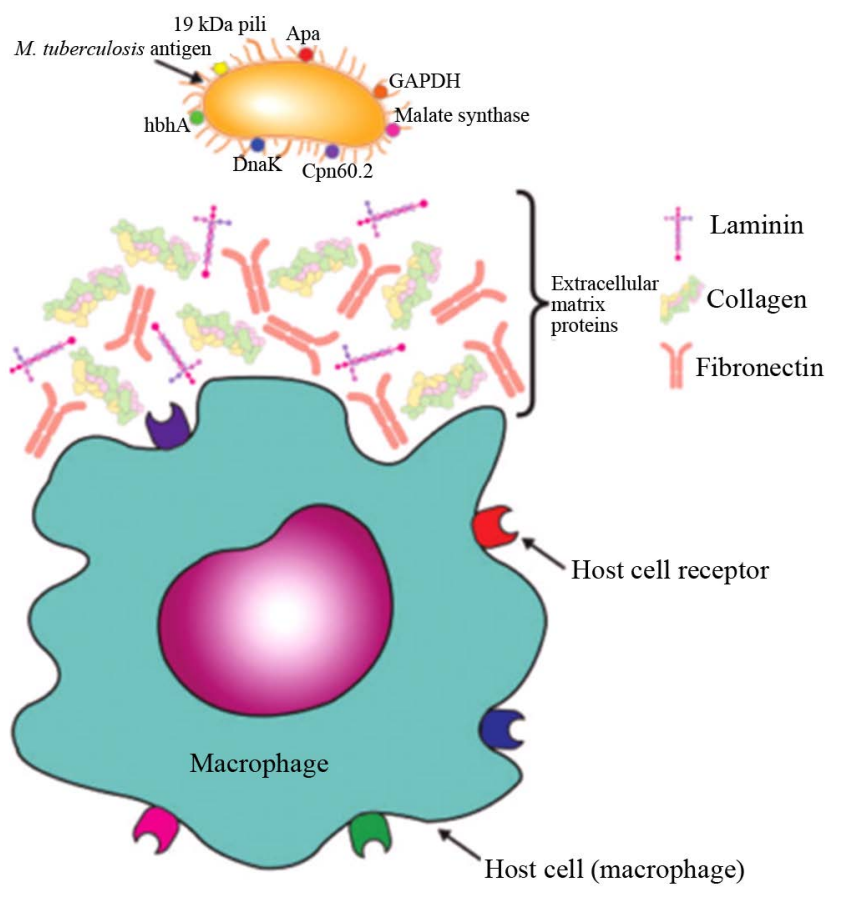

Figure 7. Selected $M$. tuberculosis adhesins and the multiple pathways available for initiating host interaction and colonization [31]. 
elimination of the bacterium. These include:

M. $t b$ requirement of a membrane protein called Rv3671c during in vivo replication. Rv3671c protein enables $M$. $t b$ survival in the acidic milieu of the macrophages/phagosome. In ex vivo environment, the bacterium does not depend on the protein under standard growth conditions. However, in a susceptible host cell' alveolar macrophages, without Rv3671c, the bacterium becomes acidified and is killed [33]. Therefore for survival, it continuously synthesizes the protein and multiplies in the host cellular environment. This protein is therefore a potential target for tuberculosis anti infective drugs.

$M . t b$ is a fastidious slow growing bacterium with long generation time. M. tuberculosis in vivo would most probably be limited for oxygen and nutrients, and therefore would display rather long generation times. However, in laboratory-grown cultures, these constraints do not exist and yet $M$. tuberculosis generation time is $\sim 18 \mathrm{~h}$ on the average, while $M$. smegmatis divides every 3 to $5 \mathrm{~h}$. Multiple properties of the tubercle bacillus contribute to its slow growth, and the unique composition of the mycobacterial envelope is likely to present permeability barriers. Since cell wall lipids constitute a high proportion of the dry weight of mycobacteria [34] and cell wall synthesis imposes a considerable energy demand on the cell, its biosynthetic rate may also be limiting for growth. RNA chain growth in $M$. tuberculosis was $\sim 10$ times lower than that in $E$. coli, and the low transcription rate was attributable to a low rate of transcription initiation. This reflects in a rather low content of RNA per unit of DNA compared to that in other bacteria. Thus, in M. bovis and M. tuberculosis, the RNA/DNA ratio varied between only 1:1 and 2:1 [35]. Because of $M$. $t b$ 's slow generation time, the immune system may not readily recognize the bacteria or may not be triggered sufficiently to eliminate them.

Establishment of productive infection in less than $10 \%$ of infected persons. Epidemiological data shows that most of M. tuberculosis infected population neither develops disease nor becomes infectious, and clinical disease occurs in less than $10 \%$ of infected persons. This suggest that genetic differences in the host determine immunological response, disease severity, and ultimate outcome of infection with mycobacteria. The interaction between $M$. tuberculosis and phagocytic cells results in a dynamic balance between the host defense system and the virulence factors of mycobacteria allowing the persistence of $M$. tuberculosis in the absence of disease. However in about $10 \%$ of $M$. tuberculosis infected persons, the interaction between macrophages and the tubercle bacilli may result in tissue damage characterized by tissue necrosis with the formation of cavities and dissemination of the pathogen [36]. Therefore, the remaining $10 \%$ free population can be made totally free by immunization.

M. tuberculosis is a strictly intracellular pathogen. This is an effective means of evading the immune system, particularly the ineffective antibodies and complement. In addition intracellular growth of M. tuberculosis makes it difficult for the drugs to reach the bacilli.

Mycobaterium requirement of Rm1A enzyme for growth. The mycobacterial cell wall is a complex structure composed of peptidoglycan, arabinogalactan and mycolic acids. The D-N-acetylglucosamine-L-rhamnose disaccharide connects the galactan region of arabinogalactan to the peptidoglycan via a phosphodiester linkage, critical to the structural integrity of the cell wall for mycobacterial viability. The biosynthesis of dTDP rhamnose is catalysed by four enzymes, and the first reaction is catalysed by rmlA gene encoding D-glucose-1-phosphate thymidylyltransferase (RmlA). The rm1a gene is essential for mycobacterial growth and lack of RmlA activity has profound negative effects on bacterial cell morphology and integrity [37]. RmlA is thus a potential target for the development of new antituberculosis drugs to distrupt formation of cell wall components and cellular integrity.

Macrophages are the major host cell for mycobacterial infection. When successful, macrophages eliminate mycobacterial infection through a complex network of events involving tumor necrosis factor (TNF-a) production, leading to apoptosis of infected macrophages. Mycobacteria enter macrophages using various receptors, including complement receptors (CR1, CR3 and CR4), mannose receptor, CD14, Fc receptors and scavenger receptors. A recent study by Fratazzi et al. [38] identified a cell surface mucin, CD43, the main sialoglycoprotein on leukocytes, as an important co-receptor and/or cofactor in the mycobacterial cellular uptake process. These receptors and co-receptors are potential drug targets to abort productive infection in the host.

Variable level of adenosine triphosphate. A high level of these energy molecules is required when $M$. tuberculosis is actively replicating. But when latent, the bacterium requires lower levels of ATP to power its basic functions. If the level is further reduced even a bit, that may kill the organism. This is a potential "Achilles heel" for the non-replicating bacteria as maintaining ATP levels for their core metabolism is vital.

Exploitation of malate synthase (glcB; Rv1837c) in the glyoxalate shunt. The glyoxalate shunt, a key 
pathway in fatty acid metabolism of M. tuberculosis during persistent infection, has long been hypothesized to be a weakness in the bacteria's armour that could potentially be exploited for the development of anti-tubercular therapeutics [39].

\subsection{The Opportunities Harnessed by Mycobacterium tuberculosis}

The Opportunities harnessed by $M . t b$ are the attributes of the environment, particularly the host factors which are external in origin but helpful in achieving the pathogenic objective, survival and establishment of infection by the bacterium. These include:

Behavioral indulgence in risk factors such as smoking and alcohol consumption. Both globally and regionally, TB and MDR-TB occur among men than women owing to risk factors such as smoking, alcohol consumption or imprisonment [40] which may lead to immunosuppression and predispose the subject to opportunistic infections.

Limited efficacy and use of BCG Vaccine. Bacille Calmette Guérin (BCG), the live attenuated form of $M$. bovis - the only vaccine so far available against TB was first introduced in 1921. It was developed in the 1920's by two French scientists (Albert Calmette and Camille Guerin). This vaccine provides a good protection against childhood tuberculosis. However, its efficacy has been questionable in preventing pulmonary disease in adults, especially in periequatorial regions of the developing world [41]. It has limited efficacy for protection against the disease and cannot be administered to people living with HIV. The vaccine is not commonly used in the United States because it does not always work and it may cause a positive skin test, making it more difficult to detect true TB infection. This is largely due to the fact that while BCG effectively protects infants from tuberculosis, immunity declines with age and fails to protect adults against pulmonary tuberculosis, the primary source of dissemination. The most effective medicines against TB were discovered in the 1950s; since then, other agents have been introduced with often more frequent and serious adverse events. There is an urgent need for more effective medicines and vaccines, including for children and people living with HIV.

Development and spread of antibiotic resistant strains as a result of non compliance to drug regimen. $M$. tuberculosis may be resistant to one or more drugs commonly used to treat TB. If the bacteria are resistant to more than one of the primary drugs used for therapy, the organisms are called multidrug-resistant TB (MDR$\mathrm{TB}$ ), and if the organisms are resistant to multiple first and second lines of therapy, they are called extensively drug-resistant tuberculosis (XDR-TB). Multidrug- and extensively drug-resistant tuberculosis (M/XDR-TB) is a man-made phenomenon that emerges as a result of inadequate treatment of tuberculosis and/or poor airborne infection control in health care facilities and congregate settings. In 2009, almost 330,000 new and relapsed cases of TB (5.6\% of the global burden) and more than 46,000 deaths due to TB were reported in the WHO European Region, the majority of them in 18 countries which have made it a high priority to stop TB [40]. Among the main causes for the emergence of MDR-TB is inadequate and inappropriate treatment. TB patients diagnosed should be put on appropriate treatment regimens as early as possible. They need to be counseled and supported throughout the course of treatment in order to increase their adherence to treatment. The currently available treatment for TB, DOTS (directly observed treatment, short course), lasts for an exhausting 6 months. The first 2 months involve a strictly scheduled and monitored intake of four drugs: Isonicotinic acid hydrazide (isoniazid; INH), rifampicin (RIF), pyrazinamide (PZA), and ethambutol (EMB). This phase is followed by a continuation phase of 4 months of INH and RIF. Resistance to first line anti-TB drugs has been linked to mutations in at least 10 genes; katG, inhA, ahpC, kasA and ndh for INH resistance; rpoB for RIF resistance, embB for EMB resistance, pncA for PZA resistance and $r p s L$ and $r r s$ for Streptomycin (STR) resistance [42]. Mutations in the genome of M. tuberculosis that can confer resistance to anti-TB drugs occur spontaneously with an estimated frequency of $3.5 \times 10^{-6}$ for INH and $3.1 \times 10^{-8}$ for RIF. Because the chromosomal loci responsible for resistance to various drugs are not linked, the risk of a double spontaneous mutation is extremely low: $9 \times 10^{-14}$ for both INH and RIF [43]. MDR-TB, defined as resistance to at least INH and RIF will thus occur mainly in circumstances where sequential drug resistance follows sustained treatment failure. In addition, poor quality DOTS implementation and MDR-TB management are seriously contributing to an increase in M/XDR-TB. These factors are harnessed by the bacterium as opportunities to replicate and perpetuate itself in the host.

Lack of automated rapid methods for diagnosis of TB and rifampicin resistance. Current methods of TB diagnosis involving examination of sputum samples for the tubercle bacterium are labour intensive. A cheap, quick and reliable method that could be easily used in developing countries is needed. Scientists from New 
Zealand recently reported that honeybees could be trained to detect some of the volatile compounds released by laboratory grown $M$. tuberculosis. It remains to be seen whether these volatile compounds are also released during disease, and the practicability of the research. However, if the compounds are present in detectable concentrations in the breath of TB patients, then this could be a game-changer in the battle against this pathogen [44]. Although an automated rapid nucleic acid amplification test has been endorsed by WHO recently, this technology and other WHO - endorsed diagnostic methods are not yet widely available in most countries, particularly in sub-saharan Africa and Asia where the disease is of high-burden [40]. The unavailability of the rapid methods are serious challenges to early detection of the pathogen, thereby enhancing opportunity for persistence of the bacterium in the population. Therefore, the introduction of rapid methods are urgently required and should be made available in any resource limited countries for rapid point of care diagnosis and to mitigate $M$. $t b$ infection.

MDR-TB is under-diagnosed in children, with a consequent risk of drug resistance spreading in some regions and poor contact-tracing in some settings. There is a lack of paediatric diagnostic tools and inadequate surveillance and reporting of TB in children. TB care for children is not consistently integrated into HIV and primary health care and maternal and child health programmes. Patient-centred approaches are not fully established in most high-burden MDR-TB countries and there is a lack of mechanisms/initiatives for community based treatment [40]. Consequently, management of TB in children is outdated in some countries.

The pathogenic synergy of coinfection of the Human Immunodeficiency Virus (HIV) and Mycobacterium tuberculosis. These pathogens induce the acquired immunodeficiency syndrome (AIDS) and tuberculosis (TB) respectively, the two major communicable diseases with severe public health impact worldwide. Estimates of the World Health Organisation (WHO) and UNAIDS reveal a prevalence that around 33 million individuals were infected with HIV and one third of the world's population carries $M$. $t b$. While both infections represent global public health problems in their own right, their combination is particularly threatening due to considerable mutual interactions: In HIV-positive individuals infected by $M$. $t b$, the risk to develop active TB is 21 - 37 times higher than that of the HIV-negative population [45]. As a consequence, TB has become the leading cause of mortality for people living with HIV/AIDS, even in regions where highly active antiretroviral therapy (HAART) has been implemented. HIV is the most potent force driving the TB epidemic in countries with a high prevalence of HIV infection. Currently, this "dreadful synergistic duet” of AIDS/TB is exerting its detrimental effects in settings where HIV and $M$. $t b$ prevalence is highest (such as in Sub-Saharan Africa, India, Russia or Latin America) and where multidrug- (MDR) and extensively drug resistant TB (XDR-TB) are present [46].

Difficulty of TB screening in HIV-infected persons. HIV-infected TB patients often lack classic TB symptoms. Up to $30 \%$ of HIV-infected TB patients with pulmonary TB have a normal chest radiograph. Sputum smears may be negative in 50\% or more and currently, no internationally accepted, evidence-based approach to screening [47]. Chronic cough, or any other single symptom, is not sufficiently sensitive for TB screening in people with HIV. All these factors add impetus for the bacterium to consume the patient undetected.

Immigration. Unfavorable economic winds, wars and civil strives are the major driving forces in emigration particularly of people whose TB status are not known, from one country to the other. Collaboration mechanisms for a continuum of care between countries (cross-border TB control, migrant labour) are lacking or inadequate. TB can affect anyone, but it is most common among immigrants from countries with high levels of TB. Undiagnosed smear-positive patients are the main source of secondary infection in most communities. TB can therefore be considered an environmental problem in which TB bacilli, spread by undiagnosed or ineffectively treated contagious cases. It represents a pollutant that spoils the quality of the air and makes it unhealthy for all community members putting them at risk of infection. Compulsory testing and certification from TB infection can be mandated (as travel restriction is not acceptable) for immigrants, as necessary measures to curtail the opportunity for dissemination of the disease.

Immune status of the host. People whose immune systems are weak because of debilitating illness, medications that affect the immune system, infancy, old age, malnutrition, unhygienic or crowded living areas, alcoholism, or intravenous drug abuse highly predispose the susceptible host to $M$. $t b$ infection and development of active disease.

Stigmatization. Public health education is inadequate, leading to a prevailing stigma. Individuals with TB symptoms such as a persistent cough often face significant social and economic barriers that delay their contact with health systems in which an appropriate diagnosis might be made, including difficulties in transport to health facilities, fear of stigmatization if they seek a TB diagnosis, and lack of social support to seek care when they fall sick. Stigma and discrimination associated with MDR-TB worsen adherence to treatment. 
Malnutrition, poverty, homeless people living in crowded, unclean conditions are vulnerable to infection. TB is one of the ailments categorized as diseases of poverty. The association between malnutrition and disease is well recognized, but the explanation for the association is complex. Energy needs of TB patients are increased because of the disease itself. The current recommendations for TB patients are based on the nutrient and energy requirements for hyper catabolic and undernourished patients. (Approximately 35 - 40 kCal per kilogram of ideal body weight). The protein intake of the diet is important to prevent the wasting of body stores (for example muscle tissues). An intake of 1.2 - $1.5 \mathrm{~g}$ per kilogram body weight or $15 \%$ of energy of total daily intake or approximately 75 - 100 g per day will be sufficient. A good multivitamin and mineral supplement, providing $50 \%$ - $150 \%$ of the recommended daily allowance, is advisable. However, susceptible subjects in high TB impacted regions of the world live in poverty as they could not even afford the specified basic needs in the "Maslows Hierachy of Human needs"' and are therefore vulnerable to TB infection. These factors are potential opportunities on which TB rides for sustenance and dissemination of the infection. Marginalized populations (homeless, migrants, etc.) and vulnerable groups (such as children and pregnant women) lack access to adequate diagnosis and treatment. Consistent intake of balanced diet, consistent income, comfortable home, living environment, regular exercise and healthy living are crucial to wall-off infection and diseases. Alli et al. [40] reported that oxidative stress and reduced vitamins $C$ and $E$ levels are associated with rifampicin resistance in Multi-drug resistant tuberculosis, and recommended the administration of the vitamins to reduce severity of the disease. Patient should have a diet to mitigate tuberculosis, by avoiding fatty foods that bother over- nutrition and the liver, that may cause digestive problems. It is preferably a mixed and varied diet that contains sufficient protein and raw vegetables rich in vitamins such as dates, raisins, lemons, grapes, and quinces (in haemoptysis), celery, beetroot, carrots, garlic, soy, honey, royal jelly and pollen. Rest after lunch at least 1 - 2 hours is needed for patients under intensive care. To mitigate the impact of TB, provision of jobs, good housing design, urban regeneration, and slum upgrading programs might therefore have a role to play in TB control. In addition, these are consistent with the Millennium Development Goal of "by 2020, to achieve a significant improvement in the lives of at least 100 million slum dwellers" [48].

Anatomical vulnerability of the lungs. The lungs are particularly vulnerable to infection due to limitations in anatomical barriers allowing for airflow, making effective, but non-pathologic, pulmonary immunity that is vital for successful host defense [49]. In immunocompetent patients, M. tuberculosis infection usually starts in the lower lobes, but TB lesions tend to develop in the upper lobes of the lungs [50], due to volumetric reasons, because the lower lobes are bigger than the upper lobes. On the other hand, the upper lobes have higher oxygen pressure, which favors the growth of the bacilli [51]. The bacillary growth in immunocompetent patients leads to a strong inflammatory response with wide production of necrotic tissue, which exceeds the structure-forming capacity of fibinrogen and collagen fibres, and eventually liquefies the tissue. Liquefaction allows extracellular bacillary growth and thus a stronger inflammatory response, with increased numbers of infected macrophages around the necrotic tissue. This process generates an extensive parenchymal damage, including bronchial destruction that leads to the drainage of liquefied material and the characteristic cavity formation [14].

Slow response of the cellular immune response in $\boldsymbol{M}$. $\boldsymbol{t} \boldsymbol{b}$. The first components of host defense to encounter pathogens that have breeched anatomical barriers constitute innate immunity which includes mononuclear phagocytes, natural killer cells and other innate cells of lymphoid origin, neutrophils, and serum factors including complement and natural antibodies. Encounter with foreign microbes through conserved pattern recognition receptors activates innate sentinels known as dendritic cells to stimulate T- lymphocytes, which in turn provide help to B-cells and orchestrate adaptive immune responses. Adaptive immunity has evolved in vertebrates to include both cellular and humoral components, with T- cells and B-cells mediating these effects, respectively. Tcells target and promote apoptotic killing of pathogen-infected cells either directly or through cytokine activation of neighboring immune cells, whereas B- cells synthesize antibodies that neutralize invasion and target infectious agents for destruction [52]. Upon aerosol infection with Mycobacterium tuberculosis, the acquired cellular immune response is slow to be induced and to be expressed within the lung. This slowness allows infection to become well established; thus, the acquired response is expressed in an inflammatory site that has been initiated and modulated by the bacterium. $M$. $t b$ has a variety of surface molecules that interact with the innate response, and this interaction along with the autoregulation of the immune response by several mechanisms results in less-than-optimal control of bacterial growth [53]. Once the non-replicating bacilli return to alveolar spaces through inspiration of infected aerosols, they can start to grow and produce infective foci because of a delay in the attraction and arrival of immune T-cells. This enables constant endogenous reinfection of the host and de- 
velopment of drug resistance.

The global prevalence of tuberculosis. TB is a worldwide health problem. $27 \%$ of the global population (about 1.9 billion people) currently has latent TB, and $80 \%$ of the global burden is borne by only 22 countries of which India and China bear one-third of the total TB burden [45]. South Africa was classified as a high-TB burden country and was ranked 7th by the WHO. Tuberculosis remains a major public health problem in India with the country accounting for one-fifth or $26 \%$ of all tuberculosis cases reported globally. TB is still one of the leading causes of mortality in India killing two persons every 3 minutes and nearly 1000 every day. Of the estimated global annual incidence of 8.8 million TB cases, nearly 2.3 million cases were estimated to have occurred in India. In a review of the Indian Revised National Tuberculosis Control Programme (RNTCP) conducted by the Government of India, in collaboration with the World Health Organization (WHO) and Swedish International Development Agency (SIDA) in 1992, it was concluded that the national programme suffered from managerial weakness, inadequate funding, over-reliance on $\mathrm{x}$-ray, non-standard treatment regimens, low rates of treatment completion, and lack of systematic information on treatment outcomes [54]. All of these findings as obtainable in other TB endemic and developing countries, added impetus and opportunity for the continuous spread of tuberculosis. The World Health Organization (WHO) estimated that 1.4 million people died from tuberculosis in 2010 [40]. An estimated 12\% of incident cases occurred in patients who were HIV positive. Consequently, the high global burden presents opportunity to the bacteria for exposure of contacts and geometric rate of infection, to decimate individuals, economies and human productivity (Figure 8).

Aerosols by inspired air are crucial for latent tuberculosis infection. Production of aerosols is usually linked to the spread of the disease in the human population. Aerosols serve the function of conditioning the inspired air [56]. Effectively, aerosols are made mainly at the upper bronchial tree from the alveolar fluid, to provide humidity and to warm the rapidly inspired air. This implies that there is the constant possibility of endogenous reinfection.

TACO assisted entry. Mycobacterium tuberculosis is internalized by host macrophages and are able to survive intracellularly because of their ability to recruit and retain a protein called TACO (tryptophane aspartatecontaining coat protein) at the mycobacterial phagosome. TACO prevents vesicle fusion with the lysosomes that would normally destroy intracellular bacteria. Mycobacteria preferentially enter cells at cholesterol-rich areas of the cells' plasma membrane and are subsequently sequestered in TACO-coated phagosomes, preventing lysosomal delivery and promoting bacterial survival. Agents designed to target the cholesterol-mediated entry of $M$. tuberculosis may be developed as tuberculosis therapeutics [57].

Interplay of host and pathogen factors. The survival and long-term persistence of $M$. $t b$ within the host macrophage involves a dynamic equilibrium between competing processes initiated by the host cell at one end, and by the pathogen on the other. Various factors that regulate the course and outcome of infection are manifold and involve a complex interplay between the immune system of the host and survival strategies by the bacteria. In response to infection, the host macrophage initiates a range of anti-microbial responses. These include the phagosome-lysozome fusion pathways, activation of the autophagic machinery, generation of reactive oxygen/nitrogen species, and induction of processes leading to cell apoptosis, among others. Therefore, survival of the intracellular $M$. $t b$ depends upon its capacity to attenuate these host bactericidal pathways. In addition, the pathogen is also required to manipulate the metabolic machinery of the host cell, so as to ensure a nutrient rich environment that promotes its sustenance [58]. A compromised immune system provides opportunity for the bacterium to multiply and establish disease.

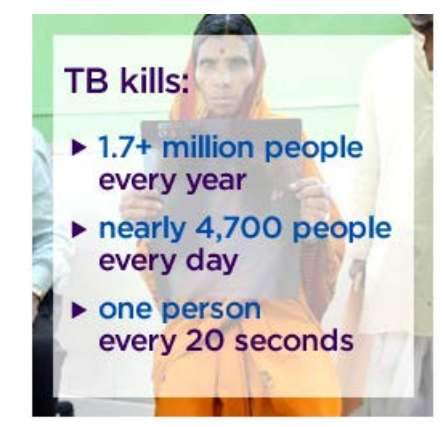

Figure 8. TB global mortality [55]. 
Covert existence of Smear-Negative Multidrug Resistant Tuberculosis (snMDR-TB). snMDR-TB patients are defined as smear-negative pulmonary TB (SN-PTB) patients whose clinical profiles are similar to those of MDR-TB patients, and have the potential possibility to become a MDR-TB patient. The basic issues about snMDR-TB are how to determine whether a patient is snMDR-TB and how many snMDR-TB cases there are in the real world. The majority of new TB cases (80\%) occurred in 22 countries and substantial proportion (35\%) were identified as SN-PTB [59]. It seems very likely that there must be SN-PTB cases which are smearnegative MDR-TB (snMDR-TB). It was hypothesized that SnMDR-TB is an important source of MDR-TB and that the number of snMDR-TB cases is likely greater than that of MDR-TB cases. The concept of snMDR-TB has been difficult to define and predict effectively. However, it is considered to be a significant hidden problem for MDR-TB control. It was recognized that if TB epidemic is to be effectively controlled, there is need to focus not only on the treatment of active TB (ATB), but also on prevention and treatment of latent tuberculosis infections (LTBI). Similarly, if MDR-TB epidemic is to be controlled, focus must be on both MDR-TB and snMDRTB simultaneously. However, a kind of vicious circle with a certain delay effect exists between snMDR-TB and MDR-TB. [60]. Therefore, to better control MDR-TB, it is necessary to pay greater attention to snMDR-TB, conduct further research and develop targeted therapeutic strategies.

Helminthic infection downregulates immunity, clinical response and vaccination against tuberculosis. Despite efforts to control TB and helminthiasis, both diseases are still the major global health problems especially in sub- Saharan Africa [61]. Tuberculosis and helminthiasis affect approximately one third of the world's population. The geographic distributions of both diseases overlap substantially, making coinfections a common presentation and it has been estimated that one-third of the world's population harbors at least one species of the helminthes [61]. For instance, Ascaris lumbricoides infection alone affects more than one billion people and almost all of cases of $A$. lumbricoides infection are prevalent in the developing world [62]. Intestinal helminth infection has been shown to have a negative impact on both anti-Mycobacterium tuberculosis immunity and clinical response to tuberculosis therapy. The widespread existence of helminth infection in areas of high TB incidence and the consequent immunemodulation may affect the ability of the host to respond to subsequent infections including $M$. tuberculosis. Chronic helminth infections have a tremendous impact on the host immune response against tuberculosis, either by shifting Th1 immune response to Th2 or by enhanced production of regulatory cells and their respective cytokines. Innate immune response against tuberculosis is also diminished during chronic helminth infections [63].

Macrophage activation can be divided into classical Th1 mediated and alternative Th2-mediated pathways. Classically activated macrophages (CAMs) up-regulate nitric oxide synthase (NOS), which oxidizes l-arginine to nitric oxide and citrulline. Nitric oxide promotes killing of intracellular $M$. $t b$ [64]. In contrast, arginase-1 expression is induced in alternatively activated macrophages (AAMs), and the enzyme hydrolyzes the same substrate l-arginine to urea and lornithine. AAM constitute a major cellular pathway that compromises the helminth-infected host's ability to restrict Mtb [65] hence gene expression of AAM markers is elevated in lungs of co-infected host. AAMs induction is due to elevation of Th2 cytokines like IL-4. Consequently, AAMs induction is one mechanism through which helminth-induced Th2 cytokines impinge on immune control of $M$. $t b$ [66]. Furthermore, macrophages exposed in vitro to Th2 cytokines are less efficient in killing intracellular $M t b$ because their autophagy pathway is blocked [67]. Therefore, it is possible that the Th2 response induced in co-infected animals during the early infection extends the duration of the AAM phenotype of the lung, allowing $M$. $t b$ to resist autophagy-mediated killing for a longer time than what would occur in animals infected with $M$. $t b$ alone [65]. Hence, individuals with preexisting helminth infection are more susceptible to tuberculosis infection.

\subsection{Threats to Mycobacterium tuberculosis}

The Threats to $M$. $t b$ are the attributes of the environment which are external in origin but inimical to the pathogenic objective, survival and establishment of infection by the bacterium. These include:

The development and use of sensitive combination of microbiological tests as the gold-standard for diagnosis. This is particularly applicable in HIV infected patients. The tests may include, 2 sputum smears, chest radiography, CD4+ counts.

Evolution of specific diagnostic methods to detect mycobacteria. A cocktail of tests have been developed for the diagnosis of TB; namely, Acid-fast bacillus smear, TB Screening Tests, Bacterial Wound Culture; Susceptibility Testing, Mycobacteria tuberculosis nucleic acid amplification test (TB NAAT), Body Fluid Analysis, 
Sputum Culture, Adenosine Deaminase, Chest Radiography, Ultrasonography and Enzyme-Linked Immunosorbent Assay. A Quantiferon (QFT-g) test was approved in 2005 by the US Food and Drug Administration (FDA) that basically detects the presence of interferon gamma release protein (IFN-g) from the blood of sensitized patients when incubated with the early secretory antigenic target-6 (ESAT6) and culture filtrate protein 10 (CFP10) peptides [18]. The test is as sensitive as, and more specific than, the tuberculin skin test and has been recommended as a screening tool for diagnosing disease as well as infection. An acid-fast bacillus (AFB) smear is used to look for AFB in a sample from the site of suspected infection. An AFB smear may be done in conjunction with a molecular test for TB termed nucleic acid amplification test (NAAT). These tests can provide a presumptive diagnosis, which can aid in the decision of whether to begin treatment before culture results are available. Results of an AFB smear (and NAAT) are typically available several hours after a sample is collected, while an AFB culture typically takes days to weeks. AFB cultures are used to diagnose active M. tuberculosis infections, infections due to another member of the Mycobacterium family, or to determine whether TB-like symptoms are due to another cause. They are used to help determine whether the TB is confined to the lungs (pulmonary disease) or has spread to organs outside the lungs (extrapulmonary disease). AFB cultures can also be used to monitor the effectiveness of treatment and can help determine when a patient is no longer infectious.

Annual TB test. The Centers for Disease Control and Prevention recommends that people at high risk for TB (such as those with HIV infection or immigrants from areas with high rates of TB) get a skin test yearly so that treatment can begin immediately if they are found to have TB.

Prioritizing genomic drug targets in Mycobacterium tuberculosis. The search for drugs to prevent or treat infections remains an urgent focus in infectious disease research. Traditional prioritization approaches to drug target identification, such as searching the literature and trying to mentally integrate varied criteria, can quickly become overwhelming for the drug discovery researcher. This can be overcome by computationally integrate different criteria to create a ranking function that can help to identify targets. This approach has been applied on the genome of Mycobacterium tuberculosis, to evolve new drug treatments because of emerging drug-resistant strains. The cost of research and development in the pharmaceutical industry has been rising steeply and steadily in the last decade, but the amount of time required to bring a new product to market remains around ten to fifteen years [68]. This problem has been labeled an "innovation gap," and it necessitates investment in inexpensive technologies that shorten the length of time spent in drug discovery. The target identification stage is the first step in the drug discovery process [69] and as such can provide the foundation for years of dedicated research in the pharmaceutical industry. As with all the other steps in drug discovery, this stage is complicated by the fact that the identified drug target must satisfy a variety of criteria to permit progression to the next stage. Important factors in this context include homology between target and host (to prevent host toxicity such homology must be low or nonexistent) [70]; activity of the target in the diseased state [71] [72]; and the essentiality of the target to the pathogen's growth and survival. Assess Drug Target software that ranks the genes in a genome according to a given set of weighted criteria was developed by Hasan et al. [73] to prioritize drug target on the basis of specific features and genomic characteristics of $M$. tb (Growth-essentiality and epidemiology, Druggable protein domains, Metabolic chokepoints, Availability of structural clues, Presence or absence of a close homolog, Gene expression in disease models, GA implementation for optimizing persistence targets). Assess Drug Target provides a simple framework for integrating the vast amount of biological data that can be used in the drug target identification stage. The various microarray models of latent TB allow us to prioritize which targets could be selected for combating TB persistence.

Development of a seemingly elusive vaccine. As of now, no promising vaccine has come in to the scene so far for tuberculosis in spite of various attempts in coming up with a DNA vaccine [74]-[76]. The vaccine development has again come to picture after lacunae of several decades where the development pipeline now includes seven vaccine candidates that are being tested in humans. Two non- replicating viral vector vaccines have very recently entered the first phase efficacy trial in infants (the first such trial in 80 years) and in human immunodeficiency virus-infected adults [77]. Yet we have a long way to go for an effective vaccine which would take care of all the thriving forms of this recalcitrant bacterium.

Live imaging using computer tomography and positron electron tomography. Part of the reason why latent TB is a relatively neglected area of research is that it is difficult to characterize. Early studies of latent TB were based on autopsy of dead patients, the results of which gave confusing results that were different greatly from one study to the next. To overcome these challenges, advanced techniques were developed. Live imaging is a particularly exciting development, using CT (computerized tomography) and PET (positron emission tomo- 
graphy) scanners to look directly at TB lesions developing in the lungs of patients. PET scans illuminated areas of inflammation using radiolabelled tracers, while CT takes high-resolution X-ray images of the body, allowing the 3D structure of the scanned region to be reconstructed. These are widely used in cancer therapy, but have not been applied previously to infectious diseases such as TB. Using this combination of CT and PET imaging every single lesion in a patient can be seen, measure, study its functional status, and then treat the patient with drugs, and observe if the lesions heal or get worse.

Development and application of Infecton for imaging deep seated infections. A new radioimaging agent, Tc-99m ciprofloxacin (Infecton) has been developed to detect deep-seated bacterial infections, such as intra-abdominal abscesses. Patients with suspected bacterial infection have been subjected to Infecton imaging and microbiological evaluation, reporting an overall sensitivity of $85.4 \%$ and a specificity of $81.7 \%$ for detecting infective foci. Sensitivity was higher (87.6\%) in microbiologically confirmed infections. Infecton may aid in the earlier detection and treatment of deep-seated infections such as TB, and monitoring clinical response and optimising the duration of antimicrobial treatment [78].

Selective isolation of TB patients by reintroduction of sanatoria to provide state-of-the-art palliative care to dying patients in a safe and dignified setting. In this way, destitute people for whom treatment has failed could voluntarily reside on a long-term basis with social, educational, and recreational facilities, and receive good nutrition and care within an infection-controlled setting, thereby reducing transmission within the community and to family members. Furthermore, avoiding close contact with people infected with TB until they are no longer contagious and use of Personal protective equipment such as a facemask (called respirator) that can prevent the spread of TB if close contact with someone who has TB is necessary. This is important in the curtailment of occupational hazards and hospital acquired infections.

\section{Discussion}

Global integrated innovative approaches are required to combat and sabotage one of the oldest, deadly, and most resilient enemies of the mankind. At the level of individual, M. tuberculosis impacts humans in the most productive phase of their life thereby sucking their income, decreasing the productivity and thus inflicting a great loss in human capital. On the average one person infects fifteen others before finally getting successfully treated; the death statistics is alarming with one death every twenty second. The right to health and hope is one of the fundamental rights that are robbed by this enemy of the mankind. The conquest of the Mycobacterium to the mankind needs to be the priority of the synergistic efforts by the scientific community. Innovative approaches from drug development that includes quest for effective molecular scaffolds and their derivatives, both old and new, as well as reengineering delivery strategies for the drug to penetrate the recalcitrant stubborn microbe are imperative.

Modern therapy relies on a combination of potent bactericidal agents, such as isoniazid, rifampicin and pyrazinamide, in a treatment within six to nine month duration.

Excessive use of antibiotics has given rise to a new multidrug resistant (resistance to frontline Isoniazid and Rifampicin antibiotics) and extremely drug resistant strains leading to what we call MDR and XDRTB. The complex milieu of Mycobacterium tuberculosis and its intelligent survival instinct by virtue of adaptive diversification in tuberculosis disease have been a major obstacle that hinders the development of shorter treatment regimens to eradicate the disease.

From the foregoings, it is no gainsaying the fact that TB disease burden is so enormous that scientist can no longer rely on traditional methods of research alone but explore holistic innovative research approaches, even at the molecular level, in looking for better alternatives and treatment modules to address the issue of this pathogen.

The strengths of $M$. $t b$ are attributes of internal origin of the bacterium, which are helpful to achieve the pathogenic objective, while the weaknesses are also attributes of internal origin which are harmful to achieve the pathogenic objective.

The opportunities utilized by $M$. $t b$ are attributes of external origin which are helpful to achieve the pathogenic objective, while the threats are also attributes of external origin which are harmful to achieve the pathogenic objective and may be adapted as potentials for elimination of the bacterium.

Having identified each category of the concept, a $2 \times 2$ contingency table is drawn and the identified factors are allocated into each category (Table 1 ). 
Table 1. A $2 \times 2$ contingency table of the SWOT analysis of Mycobacterium tuberculosis.

\begin{tabular}{|c|c|c|}
\hline $\begin{array}{l}\text { Internal origin } \\
\text { (attributes of the } \\
\text { organization) }\end{array}$ & $\begin{array}{l}\text { STRENGTHS } \\
\text { 1) Possession of mycothiol. } \\
\text { 2) Highly contagious at low dosage. } \\
\text { 3) High cell wall content of mycolic acid. } \\
\text { 4) Replicates in alveolar macrophages. } \\
\text { 5) Extrapulmonary multiorgan involvement. } \\
\text { 6) Dual polymorphism. } \\
\text { 7) Variable metabolic states. } \\
\text { 8) Delayed seeding of the bacterium to the mediastinal } \\
\text { lymph nodes. } \\
\text { 9) Delayed macrophage apoptosis. } \\
\text { 10) Intrinsic resistance of the latent bacilli. } \\
\text { 11) Shifts to glyoxylate pathway during lipid metabolism } \\
\text { in lieu of glucose. }\end{array}$ & $\begin{array}{l}\text { WEAKNESSES } \\
\text { 1) Establishes productive infection in only } 10 \% \text { of } \\
\text { infected subjects. } \\
\text { 2) Requires host membrane proteins Rv3671c } \\
\text { during in vivo replication. } \\
\text { 3) } M \text {. tb is a strictly aerobic intracellular pathogen. } \\
\text { 4) Variable levels of ATP. }\end{array}$ \\
\hline $\begin{array}{l}\text { External origin } \\
\text { (attributes of the } \\
\text { organization) }\end{array}$ & $\begin{array}{l}\text { OPPORTUNITIES } \\
\text { 1) Antibiotic resistance owing to inappropriate drug } \\
\text { treatment. } \\
\text { 2) Smoking and alcohol consumption. } \\
\text { 3) Limited efficacy of BCG Vaccine in adults. } \\
\text { 4) Limited facility for diagnosis of TB. } \\
\text { 5) Pathogenic synergy of coinfection with HIV. } \\
\text { 6) Immune status of the host. } \\
\text { 7) Immigration. } \\
\text { 8) Malnutrition, poverty, undignified living conditions. } \\
\text { 9) Anatomical vulnerability of the lungs. }\end{array}$ & $\begin{array}{l}\text { THREATS } \\
\text { 1) Development and application of infecton. } \\
\text { 2) Inauguration of annual TB tests. } \\
\text { 3) Selective isolation and reintroduction of } \\
\text { Sanatoria. } \\
\text { 4) Prioritizing genomic drug targets. } \\
\text { 5) Sustenance of the global TB funds. } \\
\text { 6) Development of potent vaccine. } \\
\text { 7) Characterising TB using live imaging by } \\
\text { computer tomography and positron electron } \\
\text { micrography. } \\
\text { 8) Development and use of sensitive } \\
\text { microbiological tests as gold standard. }\end{array}$ \\
\hline
\end{tabular}

Researchers and pharmaceutical corporations should develop collaborative researches to evolve interventions and protocols targeted at decreasing all the factors that present as strengths and opportunities for the bacterium, as indicated in Table 1, and similarly develop research and protocols targeted at increasing on all of the factors that present as weaknesses of and threats to the bacterium, with a view to mitigating the impact and eliminating the pathogen.

The factors identified in this present study are inexhaustive as research is a continuum. Further identification of other factors is encouraged. However, this concept provides an enduring innovative platform for a veritable paradigm shift in anti-tuberculosis research, towards the evolution of successful measures to curtail the scourge of $M . t b$.

\section{Acknowledgements}

All glory to God, the greatest scientist yesterday, today, and forever, the watershed of all intellects. All authors whose publications were reviewed to generate these findings.

\section{References}

[1] Shleeva, M.O., Kudykina, Y.K., Vostroknutova, G.N., Suzina, N.E., Mulyukin, A.L. and Kaprelyants, A.S. (2011) Dormant Ovoid Cells of Mycobacterium tuberculosis Are Formed in Response to Gradual External Acidification. Tuberculosis, 91, 146-154. http://dx.doi.org/10.1016/j.tube.2010.12.006

[2] WHO (2012) Global Tuberculosis Report 2012. World Health Organization.

[3] World Health Organization (2005) Global Tuberculosis Control: Surveillance, Planning, Financing. http://www.who.int/tb/publications/global report/en/

[4] Zhang, Y. (2004) Persistent and Dormant Tubercle Bacilli and Latent Tuberculosis. Frontiers in Bioscience, 9, 1136-1156. http://dx.doi.org/10.2741/1291

[5] McMurray, D.N. (1996) Mycobacteria and Norcardia. In: Baron, S., Ed., Medical Microbiology, 4th Edition, Universi- 
ty of Texas Medical Branch, Galveston.

[6] Mazorodze, J.H. and Baker, B. (2010) Mycobaterium tuberculosis, a Major Threat to Health in South Africa: Intracellular Survival after Treatment with Novel Drugs Designed against the Mycothiol Pathway. M.Sc Thesis, University of Stellenbosch, Stellenbosch.

[7] Pandey, A.K and Sassetti, C.M (2008) Mycobacterial Persistence Requires the Utilization of Host Cholesterol. Proceedings of the National Academy of Sciences of the United States of America, 105, 4376-4380. http://dx.doi.org/10.1073/pnas.0711159105

[8] Song, H., Sandie, R., Wang, Y., Andrade-Navarro, M.A. and Niederweis, M. (2008) Identification of Outer Membrane Proteins of Mycobacterium tuberculosis. Tuberculosis, 88, 526-544. http://dx.doi.org/10.1016/j.tube.2008.02.004

[9] Casali, N. and Riley, L.W. (2007) A Phylogenomic Analysis of the Actinomycetales mce Operons. BMC Genomics, 8, 60. http://dx.doi.org/10.1186/1471-2164-8-60

[10] Cantrell, S.A., Leavell, M.D., Marjanovic, O., Iavarone, A.T., Leary, J.A. and Riley, L.W. (2012) Regulated Alteration of Mycolic Acid Structure in the Cell Wall of Mycobacterium tuberculosis. Mycobacterial Diseases, 2, 108.

[11] Kenneth, T. (2008) A Dynamic Reinfection Hypothesis for Latent Tuberculosis Infection. Infection, 37, 80-86.

[12] Rook, G.A. and Hernandez-Pando, R. (1996) The Pathogenesis of Tuberculosis. Annual Review of Microbiology, 50, 259-284. http://dx.doi.org/10.1146/annurev.micro.50.1.259

[13] Bastian, I., Stapledon, R. and Colebunders, R. (2003) Current Thinking on the Management of Tuberculosis. Current Opinion in Pulmonary Medicine, 9, 186-192. http://dx.doi.org/10.1097/00063198-200305000-00006

[14] Cardon, P.J. (2009) A Dynamic Hypothesis for Latent Tuberculosis Infection. European Infectious Disease, 2, 111114.

[15] McKinney, J.D., Honer zu Bentrup, K., Munoz-Elias, E.J., et al. (2000) Persistence of Mycobacterium tuberculosis in Macrophages and Mice Requires the Glyoxylate Shunt Enzyme Isocitrate Lyase. Nature, 406, 735-738. http://dx.doi.org/10.1038/35021074

[16] Kumar, R. (2009) Glyoxylate Shunt: Combating Mycobacterium at Forefront. International Journal of Integrative Biology, 7, 69-72.

[17] Sharma, V., Sharma, S., Hoener zu Bentrup, K., McKinney, J.D., Russell, D.G., Jacobs, W.R. and Sacchettini, J.C. (2000) Structure of Isocitrate Lyase, a Persistence Factor of Mycobacterium tuberculosis. Nature Structural Biology, 7, 663-668. http://dx.doi.org/10.1038/77964

[18] Kumar, R. and Bhakuni, V. (2010) A Functionally Active Dimer of Mycobacterium tuberculosis Malate Synthase G. European Biophysics Journal, 39, 1557-1562. http://dx.doi.org/10.1007/s00249-010-0598-7

[19] Cole, S.T. (1999) Learning from the Genome Sequence of Mycobacterium tuberculosis $\mathrm{H}_{37} \mathrm{Rv}$. FEBS Letters, 452, 710. http://dx.doi.org/10.1016/S0014-5793(99)00536-0

[20] Diel, R., Goletti, D., Ferrara, G., et al. (2011) Interferon- $\gamma$ Release Assays for the Diagnosis of Latent Mycobacterium tuberculosis Infection: A Systematic Review and Meta-Analysis. European Respirayory Journal, 37, 88-99. http://dx.doi.org/10.1183/09031936.00115110

[21] Sester, M., Sotgiu, G., Lange, C., et al. (2011) Interferon- $\gamma$ Release Assays for the Diagnosis of Active Tuberculosis: A Systematic Review and Meta-Analysis. European Respirayory Journal, 37, 100-111. http://dx.doi.org/10.1183/09031936.00114810

[22] Andersen, P. (1997) Host Responses and Antigens Involved in Protective Immunity to Mycobacterium tuberculosis. Scandinavian Journal of Immunology, 45, 115-131. http://dx.doi.org/10.1046/j.1365-3083.1997.d01-380.x

[23] Wolf, A.J., Desvignes, L., Linas, B., et al. (2008) Initiation of the Adaptive Immune Response to Mycobacterium tuberculosis Depends on Antigen Production in the Local Lymph Node, Not the Lungs. The Journal of Experimental Medicine, 205,105-115. http://dx.doi.org/10.1084/jem.20071367

[24] Rohde, K., Yates, R.M., Purdy, G.E. and Russell, D.G. (2007) Mycobacterium tuberculosis and the Environment within the Phagosome. Immunological Reviews, 219, 37-54. http://dx.doi.org/10.1111/j.1600-065X.2007.00547.x

[25] Sly, L.M., Hingley-Wilson, S.M., Reiner, N.E. and McMaster, W.R. (2003) Survival of Mycobacterium tuberculosis in Host Macrophages Involves Resistance to Apoptosis Dependent upon Induction of Antiapoptotic Bcl-2 Family Member Mcl-1. The Journal of Immunology, 170, 430-437. http://dx.doi.org/10.4049/jimmunol.170.1.430

[26] Bermudez, L.E., Danelishvili, L. and Early, J. (2006) Mycobacteria and Macrophage Apoptosis: Complex Struggle for Survival. Microbe, 1, 372-375.

[27] Boros, D.L. (2003) The Cellular Immunological Aspects of the Granulomatous Response. In: Boros, D., Ed., Granulomatous Infections and Inflammations: Cellular and Molecular Mechanisms, Vol. 1, ASM Press, Washington DC, 1-28. http://dx.doi.org/10.1128/9781555817879.ch1

[28] Crick, D.C., Brennan, P.J. and McNeil, M.R. (2004) The Cell Wall of Mycobacterium tuberculosis. In: Rom, W.N. and 
Garay, S.M., Eds., Tuberculosis, 2nd Edition, Lippincott Williams \& Wilkins, Philadelphia, 115-134.

[29] Meena, L.S. and Rajni, S. (2010) Survival Mechanisms of Pathogenic Mycobacterium tuberculosis $\mathrm{H}_{37} \mathrm{Rv}$. FEBS Journal, 277, 2416-2427. http://dx.doi.org/10.1111/j.1742-4658.2010.07666.X

[30] Kumar, D., Nath, L., Kamal, M.A., Varshney, A., Jain, A., Singh, S. and Rao, K.V. (2010) Genome-Wide Analysis of the Host Intracellular Network that Regulates Survival of Mycobacterium tuberculosis. Cell, 140, 731-743. http://dx.doi.org/10.1016/j.cell.2010.02.012

[31] Govender, V.S., Saiyur, R. and Manormoney, P. (2014) Mycobacterium tuberculosis Adhesins: Potential Biomarkers as Anti-Tuberculosis Therapeutic and Diagnostic Targets. Microbiology, 160, 1821-1831. http://dx.doi.org/10.1099/mic.0.082206-0

[32] Esposito, C., Cantisani, M., D’Auria, G., Falcigno, L., Pedone, E., Galdiero, S. and Berisio, R. (2012) Mapping Key Interactions in the Dimerization Process of HBHA from Mycobacterium tuberculosis, Insights into Bacterial Agglutination. FEBS Letters, 586, 659-667. http://dx.doi.org/10.1016/j.febslet.2012.01.047

[33] Nathan, et al. (2008) An Unsuspecting Weakness in Tuberculosis-Potential Drug Target. Disease and Infection News.

[34] Besra, G.S. and Chatterjee, D. (1994) Lipids and Carbohydrates of Mycobacterium tuberculosis. In: Bloom, B.R., Ed., Tuberculosis, ASM Press, Washington DC, 285-306. http://dx.doi.org/10.1128/9781555818357.ch20

[35] Verma, A., Sampla, A.K. and Tyagi, J.S. (1999) Mycobacterium tuberculosis rrn Promoters: Differential Usage and Growth Rate-Dependent Control. Journal of Bacteriology, 181, 4326-4333.

[36] Druszczynska, M., Strapagiel, D., Kwiatkoska, S., Kowalewicz-Kulbat, M., Rozalska, B., Chmiela, M. and Rudnicka, W. (2006) Tuberculosis Bacilli Still Posing a Threat. Polymorphism of Genes Regulating Anti-Mycobacterial Properties of Macrophages. Polish Journal of Microbiology, 55, 7-12.

[37] Hong, Q., Yi, X., Xu, D. and Ma, Y.F. (2007) An rmlA Gene Encoding d-Glucose-1-Phosphate Thymidylyltransferase Is Essential for Mycobacterial Growth. FEMS Microbiology Letters, 275, 237-243. http://dx.doi.org/10.1111/j.1574-6968.2007.00890.x

[38] Fratazzi, et al. (2000) Tuberculosis Uptake by Macrophages. The Journal of Experimental Medicine, $192,785$.

[39] Krieger, I.V., Freundlich, J.S., Gawandi, V.B., Roberts, J.P., Gawandi, V.B., Sun, Q., Owen, J.L., Fraile, M.T., Huss, S.I., et al. (2012) Structure-Guided Discovery of Phenyl-Diketo Acids as Potent Inhibitors of M. tuberculosis Malate Synthase. Chemistry \& Biology, 19, 1556-1567. http://dx.doi.org/10.1016/j.chembiol.2012.09.018

[40] Alli, J.A., Kehinde, A.O., Kosoko, A.M. and Ademowo, O.G. (2014) Oxidative Stress and Reduced Vitamins C and E Levels Are Associated with Multi-Drug Resistant Tuberculosis. Journal of Tuberculosis Research, 2, 52-58. http://dx.doi.org/10.4236/jtr.2014.21006

[41] Fine, P.E. (2001) BCG: The Challenge Continues. Scandinavian Journal of Infectious Diseases, 33, 243-245. http://dx.doi.org/10.1080/003655401300077144

[42] Johnson, R., Streicher, E.M., Louw, G.E., Warren, R.M., van Helden, P.D. and Victor, T.C. (2011) Drug Resistance in Mycobacterium tuberculosis. Current Issues in Molecular Biology, 8, 97-112.

[43] Dooley, S.W. and Simone, P.M. (1994) The Extent and Management of Drug-Resistant Tuberculosis: The American Experience. Clinical Tuberculosis, Chapman \& Hall, London, 171-189.

[44] Suckling, D.M. and Sagar, R.L. (2011) Honeybees Apis mellifera Can Detect the Scent of Mycobacterium tuberculosis. Tuberculosis, 91, 327-328. http://dx.doi.org/10.1016/j.tube.2011.04.008

[45] WHO (2009) Global Tuberculosis Control: Epidemiology, Strategy, Financing. World Health Organisation, Geneva.

[46] Sester, M., Giehl, C., McNerney, R., et al. (2010) Challenges and Perspectives for Improved Management of HIV/ Mycobacterium tuberculosis Co-Infection. European Respiratory Journal, 36, 1242-1247. http://dx.doi.org/10.1183/09031936.00040910

[47] Khun, K.E. (2011) TB/HIV Operational Research: Needs and Recent Advances. The Scale up of TB/HIV Collaborative Activities in Asia-Pacific. National Center for TB Control, CENAT.

[48] Hargreaves, R.J., Boccia, D., Carlton, A., Evans, C.A., Adato, M., Petticrew, M. and Porter, J.D. (2011) The Social Determinants of Tuberculosis: From Evidence to Action. American Journal of Public Health, 101, 654-662. http://dx.doi.org/10.2105/ajph.2010.199505

[49] Zhang, P., Summer, W.R., Bagby, G.J. and Nelson, S. (2000) Innate Immunity and Pulmonary Host Defense. Immunological Reviews, 173, 39-51. http://dx.doi.org/10.1034/j.1600-065X.2000.917306.X

[50] Balasubramanian, V., Wiegeshaus, E.H., Taylor, B.T. and Smith, D.W. (1994) Pathogenesis of Tuberculosis: Pathway to Apical Localization. Tubercle and Lung Disease, 75, 168-178. http://dx.doi.org/10.1016/0962-8479(94)90002-7

[51] Milic-Emili, J. (1991) Topographical Inequality of Ventilation. In: Crystal, R.G. and West, J.B., Eds., The Lung: Scientific Foundations, Vol. 1, Raven Press, Ltd., New York, 1043-1051. 
[52] Maglione, J.P. and Chan, J. (2009) How B Cells Shape the Immune Response against Mycobacterium tuberculosis. European Journal of Immunology, 39, 676-686. http://dx.doi.org/10.1002/eji.200839148

[53] Andrea, M.C. (2009) Cell-Mediated Immune Responses in Tuberculosis. Annual Review of Immunology, 27, $393-422$.

[54] Central Tuberculosis Division Tuberculosis India (2011) Annual Report of the Revised National Tuberculosis Control Programme. Directorate General of Health Services, Ministry of Health and Family Welfare. Government of India Publications through Central TB Division, Accessible from location: Government of India. http://tbcindia.nic.in/

[55] WHO (2011) Roadmap for the Implementation of the Consolidated Action Plan to Prevent and Combat Multidrug- and Extensively Drug-Resistant Tuberculosis in the WHO European Region 2011-2015.

[56] Bui, T.D., Dabdub, D. and George, S.C. (1998) Modeling Bronchial Circulation with Application to Soluble Gas Exchange: Description and Sensitivity Analysis. Journal of Applied Physiology, 84, 2070-2088.

[57] Novak, K. (2000) Mycobacterium tuberculosis: Surviving on a Diet of Cholesterol and TACOs, 288, 1647.

[58] Jayaswal, S., Kamal, M.A., Dua, R., Gupta, S., Majumdar, T., Das, G., Kumar, D. and Rao, K.V.S. (2010) Identification of Host-Dependent Survival Factors for Intracellular Mycobacterium tuberculosis through an siRNA Screen. PLoS Pathogens, 6, e1000839. http://dx.doi.org/10.1371/journal.ppat.1000839

[59] Walusimbi, S., Bwanga, F., De Costa, A., Haile, M., Joloba, M. and Hoffner, S. (2013) Meta-Analysis to Compare the Accuracy of GeneXpert, MODS and the WHO 2007 Algorithm for Diagnosis of Smear-Negative Pulmonary Tuberculosis. BMC Infectious Diseases, 13, 507. http://dx.doi.org/10.1186/1471-2334-13-507

[60] Liu, J.M., Wang, W., Xu, J., Gao, M.Q. and Li, C.Y. (2014) Smear-Negative Multidrug-Resistant Tuberculosis a Significance Hidden Problem for MDR-TB Control: An Analysis of Real World Data. Journal of Tuberculosis Research, 2, 90-99. http://dx.doi.org/10.4236/jtr.2014.22011

[61] Hotez, P.J., Mistry, N., Rubinstein, J. and Sachs, J.D. (2011) Integrating Neglected Tropical Diseases into AIDS, Tuberculosis, and Malaria Control. The New England Journal of Medicine, 364, 2086-2089. http://dx.doi.org/10.1056/NEJMp1014637

[62] De Silva, N.R, Brooker, S., Hotez, P.J., Montresor, A., Engels, D. and Savioli, L. (2003) Soil-Transmitted Helminth Infections: Updating the Global Picture. Trends in Parasitology, 19, 547-551. http://dx.doi.org/10.1016/j.pt.2003.10.002

[63] Elias, D., Britton, S., Aseffa, A., Engers, H. and Akuffo, H. (2008) Poor Immunogenicity of BCG in Helminth Infected Population Is Associated with Increased in Vitro TGF-Beta Production. Vaccine, 26, 3897-3902. http://dx.doi.org/10.1016/j.vaccine.2008.04.083

[64] Chan, E.D. and Iseman, M.D. (2008) Multidrug-Resistant and Extensively Drug-Resistant Tuberculosis: A Review. Current Opinion in Infectious Diseases, 21, 587-595. http://dx.doi.org/10.1097/QCO.0b013e328319bce6

[65] Potein, J.A., Rafi, W., Kamlesh, B., Amanda, M.C., William, C.G. and Padmini, S. (2011) Preexisting Helminth Infection Induces Inhibition of Innate Pulmonary Anti-Tuberculosis Defense by Engaging the IL-4 Receptor Pathway. The Journal of Experimental Medicine, 208, 1863-1874. http://dx.doi.org/10.1084/jem.20091473

[66] Hoft, D.F., Brown, R.M. and Roodman, S.T. (1998) Bacille Calmette-Guerin Vaccination Enhances Human Gamma Delta T Cell Responsiveness to Mycobacteria Suggestive of a Memory-Like Phenotype. The Journal of Immunology, 161, 1045-1054.

[67] Harris, J., De Haro, S.A., Master, S.S., Keane, J., Roberts, E.A., Delgado, M. and Deretic, V. (2007) T Helper 2 Cytokines Inhibit Autophagic Control of Intracellular Mycobacterium tuberculosis. The Journal of Immunology, 27, 505517.

[68] Humer, F. (2005) Innovation in the Pharmaceutical Industry-Future Prospects. http://www.roche.com/fbh_zvg05_e.pdf.

[69] Terstappen, G.C. and Reggiani, A. (2001) In Silico Research in Drug Discovery. Trends in Pharmacological Sciences, 22, 23-26. http://dx.doi.org/10.1016/S0165-6147(00)01584-4

[70] Freiberg, C. (2001) Novel Computational Methods in Anti-Microbial Target Identification. Drug Discovery Today, 6, 72-80. http://dx.doi.org/10.1016/S1359-6446(01)00167-2

[71] Wang, S., Sim, T.B., Kim, Y.S. and Chang, Y.T. (2004) Tools for Target Identification and Validation. Current Opinion in Chemical Biology, 8, 371-377. http://dx.doi.org/10.1016/j.cbpa.2004.06.001

[72] Sanseau, P. (2001) Impact of Human Genome Sequencing for in Silico Target Discovery. Drug Discovery Today, 6, 316-323. http://dx.doi.org/10.1016/S1359-6446(01)01724-X

[73] Hasan, S., Daugelat, S., Rao, P.S.S. and Schreiber, M. (2006) Prioritizing Genomic Drug Targets in Pathogens: Application to Mycobacterium tuberculosis. PLoS Computational Biology, 2, e61. http://dx.doi.org/10.1371/journal.pcbi.0020061 
[74] Young, D., O’Neill, K., Jessell, T. and Wigler, M. (1988) Characterization of the Rat Mas Oncogene and Its High-Level Expression in the Hippocampus and Cerebral Cortex of Rat Brain. Proceedings of the National Academy of Sciences of the United States of America, 85, 5339-5342. http://dx.doi.org/10.1073/pnas.85.14.5339

[75] Lowrie, D.B., Tascon, R.E., Bonato, V.L., Lima, V.M., Faccioli, L.H., Stavropoulos, E., Colston, M.J., Hewinson, R.G., Moelling, K. and Silva, C.L. (1999) Therapy of Tuberculosis in Mice by DNA Vaccination. Nature, 400, 269271. http://dx.doi.org/10.1038/22326

[76] Orme, I.M. (2001) The Search for New Vaccines against Tuberculosis. Journal of Leukocyte Biology, 70, 1-10.

[77] Beresford, B. and Sadoff, J.C. (2010) Update on Research and Development Pipeline: Tuberculosis Vaccines. Clinical Infectious Diseases, 50, 178-183. http://dx.doi.org/10.1086/651489

[78] Falzon, D., Jaramillo, E., Schnemann, H.J., Arentz, M., Bauer, M., Bayona, J., Blanc, L., Caminero, J.A., Daley, C.L., Duncombe, C., Fitzpatrick, C., Gehard, A., Getahun, H., Henkens, M., Holtz, T.H., Keravec, J., Keshavjee, S., Khan, A.J., Kulier, R., Leimane, V., Lienhardt, C., Lu, C., Mariandyshev, A., Migliori, G.B., Mirzayev, F., Mitnick, C.D., Nunn, P., Nwagboniwe, G., Oxlade, O., Palmero, D., Pavlinac, P., Quelapio, M.I., Raviglione, M.C., Rich, M.L., Royce, S., Rsch-Gerdes, S., Salakaia, A., Sarin, R., Sculier, D., Varaine, F., Vitoria, M., Walson, J.L., Wares, F., Weyer, K., White, R.A. and Zignol, M. (2011) WHO Guidelines for the Programmatic Management of Drug-Resistant Tuberculosis: 2011 Update. European Respiratory Journal, 38, 516-528. http://dx.doi.org/10.1183/09031936.00073611 